\title{
Comparative study of structure and photo-induced reactivity of malonaldehyde and acetylacetone isolated in nitrogen matrices
}

\author{
A. Trivella ${ }^{1}$, S. Coussan ${ }^{1}$, T. Chiavassa ${ }^{1}$, P. Theulé ${ }^{1}$, C. Manca ${ }^{2}$, \\ and P. Roubin ${ }^{1}$ \\ ${ }^{1}$ Laboratoire PIIM, Université de Provence, Centre Saint-Jérôme, Marseille F-13 397, cedex 20, France \\ E-mail: pascale.roubin@up.univ-mrs.fr \\ ${ }^{2}$ Laboratorium fur Physikalische Chemie, ETH Zurich, Zurich CH-8093, Switzerland
}

Received May 4, 2006, revised July 14, 2006

\begin{abstract}
Structure and reactivity of the eight enolic forms (one chelated and seven non-chelated) of malonaldehyde and acetylacetone are compared through theoretical and experimental data. Ground-state geometries, energies, and vibrational frequencies are calculated with the B3LYP $/ 6-311++\mathrm{G}(2 d, 2 p)$ model chemistry. The electronic delocalisation as well as the cis/trans rotamer properties are analysed. The hydrogen bond strength of the chelated forms can be estimated by the energy difference between chelated and non-chelated forms, and its enhancement due to methyl-induced electron release is estimated at $1.7 \mathrm{kcal} \cdot \mathrm{mol}^{-1}$. UV- and IR-induced reactivity of molecules isolated in nitrogen matrices is studied by means of FT-IR spectrometry. Interconversion between rotamers is the main process observed for both molecules, only some among the seven non-chelated forms being created.
\end{abstract}

PACS: $36.20 . \mathrm{Ng}, 31.15 . \mathrm{Ar}$

Keywords: FT-IR spectrometry, cis/trans rotamer, properties, H-bond strength, electronic delocalization.

\section{Introduction}

Malonaldehyde (MA) and acetylacetone (AA) are prototypical $\beta$-diketones, whose stable enolic forms present a strong hydrogen bond (H-bond), with proton transfer between the two oxygen atoms. Figure 1 shows the eight enolic rotamers labeled $X Y Z$ : these letters are either $\mathrm{C}$ or $\mathrm{T}$, where $\mathrm{C}(\mathrm{T})$ stands for the cis (trans) configuration relative to the $\mathrm{C}-\mathrm{C}, \mathrm{C}=\mathrm{C}$ and $\mathrm{C}-\mathrm{O}$ bonds, respectively. The stable form is the chelated CCC form, and numerous studies have attempted to unravel fundamental questions as its $\mathrm{C}_{2 v}$ (symmetrical $\mathrm{H}$ position between the two oxygen atoms) or $\mathrm{C}_{s}$ (asymmetrical $\mathrm{H}$ position as shown in Fig. 1) structure, the proton transfer barrier height, and / or the estimation of the H-bond strength. Information on this latter parameter could also be brought through the $d_{\mathrm{OO}}$ distance, the $\mathrm{O}-\mathrm{H}$ stretching, height, frequency, or the energy difference between non- chelated and CCC forms. Microwave experiments have determined a $\mathrm{C}_{s}$ structure for MA with a $d_{\mathrm{OO}}$ distance measured at $255 \mathrm{pm}$ [1] whereas for AA, photon electron spectroscopy $[2,3]$ and $x$-ray diffraction $[4,5]$ have predicted a $\mathrm{C}_{2 v}$ structure. Nevertheless, electron diffraction results are contradictory $[2,6,7]$, predicting a $\mathrm{C}_{s}$ or a $\mathrm{C}_{2 v}$ structure. A recent ultra fast electron diffraction study of Zewail et al. [8] has demonstrated that, at least at the short timescale $(\sim 100 \mathrm{ps})$, the AA structure is asymmetrical with a $d_{\mathrm{OO}}$ distance of $259 \mathrm{pm}, 8 \mathrm{pm}$ larger than the previous estimation [6]. The proton transfer barrier has been estimated at $6.6 \mathrm{kcal} \cdot \mathrm{mol}^{-1}$ from the measured tunnelling splitting $\left(21.6 \mathrm{~cm}^{-1}\right)$ for MA [9-11], and besides, many theoretical studies have focussed on the description of this tunnelling process, trying to reproduce the measured splitting and to estimate the barrier height. Until the 90ies, this barrier height has been found $[11,14]$ ranging from 4.7 to 


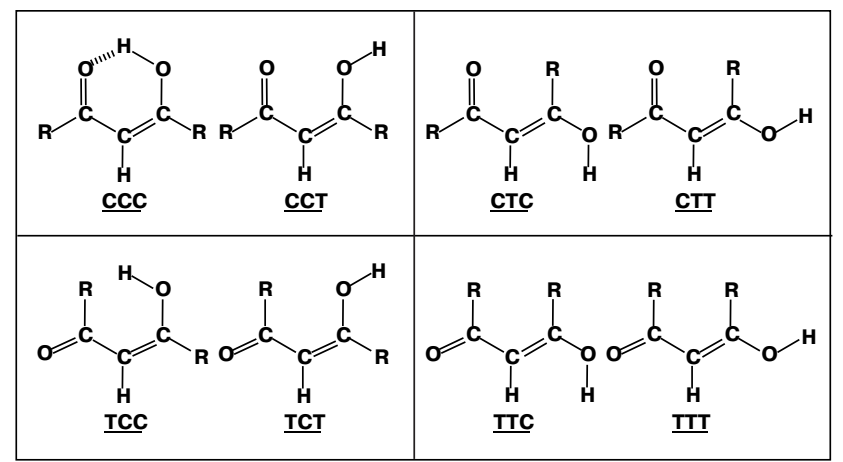

Fig. 1. Diagram of the eight enolic isomers of malonaldehyde $(\mathrm{R}=\mathrm{H})$ and acetylacetone $\left(\mathrm{R}=\mathrm{CH}_{3}\right)$.

$10.0 \mathrm{kcal} \cdot \mathrm{mol}^{-1}$, the lowest value coming from the work of Frisch et al. [13] which emphasizes the role of electron correlation. Consistently, more recent and accurate calculations [15-27] agree with lower values between 3.1 and $4.6 \mathrm{kcal} \cdot \mathrm{mol}^{-1}$. Discrepancies originate from the difficulty of describing the complex multidimensional dynamics of this proton tunnelling. For AA there is no experimental determination of the tunnelling splitting and calculations of the proton barrier are only a few [28-30], leading to similar values as for MA, between 2.5 and $7 \mathrm{kcal} \cdot \mathrm{mol}^{-1}$. Some studies also calculate the energy release due to conversion from the CCC form to the non-chelated forms, generally CCT, which is the simplest way to quantify the H-bond strength: the obtained values also decrease with the calculation accuracy increase and range between 12.4 and $15.8 \mathrm{kcal} \cdot \mathrm{mol}^{-1}$ for MA $[18,31,32]$ and between 12.0 and $18.5 \mathrm{kcal} \cdot \mathrm{mol}^{-1}$ for AA $[28,29$, 33,34]. For both molecules, infrared measurements show that the $\mathrm{O}-\mathrm{H}$ stretching mode is red-shifted and broadened due to H-bonding: in gas phase, the $v_{\mathrm{OH}}$ band is clearly observed for AA [35,36] at $\sim 2800 \mathrm{~cm}^{-1}$ (FWHM larger than $1000 \mathrm{~cm}^{-1}$ ) and has been tentatively assigned at $\sim 2950 \mathrm{~cm}^{-1}$ for MA [37,38]. In the same way, the $\mathrm{C}=\mathrm{O}$ stretching mode is red-shifted and is measured in gas phase at $1620 \mathrm{~cm}^{-1}$ for AA and at $1655 \mathrm{~cm}^{-1}$ for MA. These vibrational features indicate that the mixing of vibrations due to electronic delocalisation is larger for AA than for MA, and therefore that the H-bond is stronger: this is due to the electron release from the methyl groups. Vibrational analysis seems therefore to bring clear information on H-bond strength, whereas energy calculation uncertainties are still too large to definitely conclude about the relative $\mathrm{H}$-bond strength of the two molecules. It should be noted that work allowing a direct comparison of the two molecules, i.e. using same experimental or theoretical methods, are a very few [39-41].
Experimental data on the unstable non-chelated forms are also rare and up to now there are obtained only through photochemistry of molecules isolated in cryogenic matrices $(T<10 \mathrm{~K})$. This cold solid-state environment prevents from both major fragmentation, and relaxation to the stable CCC form. A $\pi \rightarrow \pi^{*} \mathrm{UV}$ excitation leads to the formation of several nonchelated rotamers [42-44] among the seven forms shown in Fig. 1, and subsequent resonant UV or IR irradiation of these created rotamers lead to other rotamer conversions $[45,46]$. Combining different excitations and a detailed vibrational analysis has allowed us to provide new information, especially from selective vibrational excitations, and to accurately assign the observed new isomers in the case of AA isolated in a nitrogen matrix $[45,46]$.

The aim of this paper is to present new results obtained with similar excitations in the case of MA isolated in a nitrogen matrix, and to compare the main features of MA and AA. The first part of the paper is devoted to a comparative analysis of geometries, energies and vibrational frequencies obtained with density functional theory; vibrational analysis is in this work the key ingredient for elucidating the photo-induced processes. The second part of the paper is devoted to the description of a selection of typical UV- and IR-induced phenomena observed for MA and AA isolated in nitrogen matrices and to a discussion of the general features which are observed.

\section{Structural, energetic, and vibrational analyses}

All the geometry optimizations and vibrational frequencies presented in this paper have been calculated using the B3LYP $/ 6-311++\mathrm{G}(2 d, 2 p)$ model chemistry implemented in Gaussian 98 [47] (AA) and in Gaussian 03 [48] (MA). Note that using Gaussian 98 or Gaussian 03 leads to negligible differences for the properties discussed here.

\subsection{Structural analysis}

Table 1 gathers the main geometric parameters for the eight forms of the two molecules, and Fig. 2 summarizes geometrical parameters for the chelated forms: the $\mathrm{O}-\mathrm{H}$ distance is larger, and consistently the $\mathrm{O} \cdots \mathrm{H}$ distance as well as the $d_{\mathrm{OO}}$ value are smaller, for AA than for MA. The $\mathrm{C}-\mathrm{O}-\mathrm{H}$ angle is smaller while the $\mathrm{O} \cdots \mathrm{H}-\mathrm{O}$ angle is larger, showing a stronger linear character of the $\mathrm{H}$-bond for $\mathrm{AA}$, which is consistent with a stronger H-bond. Note that the methyl groups are arranged to ensure a staggered configuration both with the $\mathrm{O}-\mathrm{H}$ bond and with the two $s p^{2}$ electron pairs of the carbonyl $\mathrm{O}$ atom.

Concerning the non-chelated forms, XXC/XXT rotamers are expected to be similar, being different by 
Table 1. Geometrical parameters of the eight enolic isomers of MA and AA, calculated with the B3LYP $/ 6-311++\mathrm{G}(2 d, 2 p)$ model chemistry. Bold characters emphasize some special features. Lengths are in $\AA$ and angles in degrees.

\begin{tabular}{|c|c|c|c|c|c|c|c|c|}
\hline & $d_{\mathrm{O}-\mathrm{H}}$ & $d_{C-\mathrm{O}}$ & $d_{C-\mathrm{C}}$ & $d_{C=\mathrm{C}}$ & $d_{C=\mathrm{O}}$ & $\mathrm{C}-\mathrm{C}=\mathrm{C}$ & $\mathrm{C}=\mathrm{C}-\mathrm{O}$ & $\mathrm{C}-\mathrm{O}-\mathrm{H}$ \\
\hline \multicolumn{9}{|c|}{ MA } \\
\hline $\mathrm{CCC}$ & 0.998 & 1.318 & 1.435 & 1.362 & 1.238 & 119.6 & 123.9 & 106.2 \\
\hline CCT & 0.961 & 1.343 & 1.463 & 1.344 & 1.214 & 126.7 & 124.1 & 110.2 \\
\hline CTC & 0.965 & 1.342 & 1.463 & 1.342 & 1.215 & 120.8 & 126.8 & 110.5 \\
\hline СTT & 0.961 & 1.348 & 1.462 & 1.339 & 1.217 & 120.4 & 122.3 & 110.4 \\
\hline TCC & 0.964 & 1.346 & 1.451 & 1.346 & 1.214 & 125.1 & 128.5 & 111.2 \\
\hline TCT & 0.960 & 1.355 & 1.460 & 1.340 & 1.216 & 124.5 & 123.1 & 110.4 \\
\hline TTC & 0.965 & 1.344 & 1.455 & 1.341 & 1.214 & 120.1 & 127.1 & 110.4 \\
\hline TTT & 0.961 & 1.349 & 1.454 & 1.338 & 1.214 & 119.6 & 122.5 & 110.7 \\
\hline \multicolumn{9}{|c|}{ AA } \\
\hline $\mathrm{CCC}$ & 1.005 & 1.324 & 1.441 & 1.368 & 1.246 & 120.8 & 121.7 & 105.9 \\
\hline $\mathrm{CCT}$ & 0.963 & 1.350 & 1.472 & 1.349 & 1.218 & 126.8 & 121.4 & 109.9 \\
\hline СТC & 0.964 & 1.358 & 1.469 & 1.352 & 1.222 & 126.9 & 121.3 & 110.0 \\
\hline CTT & 0.962 & 1.362 & 1.468 & 1.348 & 1.224 & 126.5 & 116.9 & 109.9 \\
\hline TCC & 0.963 & 1.355 & 1.466 & 1.352 & 1.221 & 130.5 & 126.6 & 111.1 \\
\hline TCT & 0.961 & 1.364 & 1.474 & 1.345 & 1.222 & 129.8 & 121.6 & 109.9 \\
\hline TTC & 0.964 & 1.363 & 1.469 & 1.349 & 1.223 & 132.4 & 120.3 & 109.8 \\
\hline TTT & 0.962 & 1.368 & 1.468 & 1.346 & 1.223 & 131.9 & 115.8 & 110.3 \\
\hline
\end{tabular}

merely a rotation around the $\mathrm{C}-\mathrm{O}$ bond which does not involve main skeletal changes, excepted for the $\mathrm{CCC} / \mathrm{CCT}$ pair which corresponds to the chelated/non-chelated conversion. XXC/XXT pair characteristics are in fact evidenced in Table 1 by an alternate large/small $\mathrm{O}-\mathrm{H}$ and $\mathrm{C}=\mathrm{C}$ bond lengths and $\mathrm{C}=\mathrm{C}-\mathrm{O}$ angle, correlated to an alternate small/large $\mathrm{C}-\mathrm{O}$ bond length. These sensitive geometrical parameters are those directly linked to the $\mathrm{C}-\mathrm{O}$ bond involved in the cis/trans conversion, and their values systematically indicate a local larger electronic delocalisation for the cis configuration. On the contrary, all the $\mathrm{COH}$ angle values are similar, no specific interaction differentiating the two partners of a pair. The TCC value is the largest for the two molecules, in agreement with steric hindrance expec-
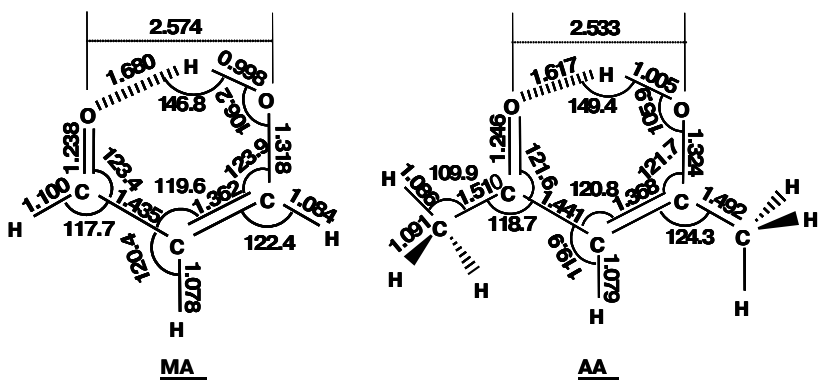

Fig. 2. Malonaldehyde (MA) and acetylacetone (AA) CCC geometries calculated by the B3LYP/6-311++G $(2 d, 2 p)$ model chemistry. Distances are in $\AA$, angles in degrees. ted to be the largest (Fig. 1). The $\mathrm{C}=\mathrm{C}-\mathrm{C}$ angle values also reflect steric hindrance: for MA, its value is larger for XCX than for XTX, the cis configuration relative to $\mathrm{C}=\mathrm{C}$ bond inducing more hindrance, while for AA, its value increases in the series CTX, TCX and TTX. This latter feature clearly shows the methyl hindrance involved when the molecule is not in CXX configuration and the maximum is obtained for the methyl syn-1,3 configuration of TTX rotamers (Fig. 1).

\subsection{Energetic analysis}

The relative energies of the non-chelated forms are given for the two molecules in Table 2. They spread

Table 2. Relative energies (in $\mathrm{kcal} \cdot \mathrm{mol}^{-1}$ ) of the seven non-chelated isomers of $\mathrm{MA}$ and $\mathrm{AA}$ calculated with the B3LYP $/ 6-311++\mathrm{G}(2 d, 2 p)$ model chemistry. The energy of the CCC chelated isomer is -267.2482947 Hartree for MA and 352.9242151 Hartree for AA

\begin{tabular}{c|c|c}
\hline \hline & MA & AA \\
\hline \hline CCC & 0 & 0 \\
CCT & 12.8 & 15.6 \\
CTC & 8.6 & 11.1 \\
CTT & 9.1 & 11.8 \\
TCC & 9.6 & 12.7 \\
TCT & 10.0 & 13.6 \\
TTC & 6.7 & 14.3 \\
TTT & 7.9 & 16.6 \\
\hline \hline
\end{tabular}


among a similar range for both molecules (5.5 $\mathrm{kcal} \cdot \mathrm{mol}^{-1}$ for $\mathrm{AA}$ and $6.1 \mathrm{kcal} \cdot \mathrm{mol}^{-1}$ for MA) but the AA rotamers are clearly at higher relative energies than the MA's. For both molecules, CCT is among of the least stable rotamers, due to hindering between the $s p^{3}$ and $s p^{2}$ electron pairs located on each oxygen atoms, while for AA, TTX high energies clearly originate from methyl syn-1,3 repulsive interactions. Note that in a XXC/XXT pair, the «C» partner is always the most stable, in agreement the local larger delocalisation deduced from geometrical parameters.

To compare the $\mathrm{H}$-bond strengths of $\mathrm{MA}$ and $\mathrm{AA}$, we compare the relative energies of the CCT forms, which are calculated at $12.8 \mathrm{kcal} \cdot \mathrm{mol}^{-1}$ for MA and at $15.6 \mathrm{kcal} \cdot \mathrm{mol}^{-1}$ for AA, i.e., a $2.8 \mathrm{kcal} \cdot \mathrm{mol}^{-1}$ energy difference. In a rough approximation, this energy difference is due both to $\mathrm{H}$-bond strength difference and to $\mathrm{H}-\mathrm{H}$ and $\mathrm{H}$-methyl interaction difference. To unravel the different origins, we have calculated with the same method the energies of ethanoic acid (EA) and formic acid (FA), for the cis and trans configurations. The cis configuration of both molecules is the most stable due to a weak interaction between $\mathrm{H}$ and $\mathrm{O}$ atoms which is similar for the two molecules, whereas the trans configuration involves either a $\mathrm{H}-\mathrm{H}$ interaction for FA, or a H-methyl interaction for EA, which can be compared with the interaction occurring in the CCT forms of either MA or AA. The cis-trans energy difference is found at $4.2 \mathrm{kcal} \cdot \mathrm{mol}^{-1}$ for $\mathrm{FA}$ and at $5.3 \mathrm{kcal} \cdot \mathrm{mol}^{-1}$ for EA and the energy difference due to $\mathrm{H}, \mathrm{H}$ or $\mathrm{H}$, methyl interaction is therefore estimated at $\sim 1.1 \mathrm{kcal} \cdot \mathrm{mol}^{-1}$. Consequently, we estimate the energy difference of the H-bond strength between $\mathrm{AA}$ and MA at $\sim 1.7 \mathrm{kcal} \cdot \mathrm{mol}^{-1}$. This rough estimation should be taken with care but is based on a systematic comparison with the same level of calculations which can give valuable trends, and this methodology should be developed at a higher level of model chemistry.

\subsection{Vibrational analysis}

Table 3 summarizes the calculated frequencies of a selection of the most intense modes of MA and AA, listed in decreasing frequency order, with their assignment as defined using the main vibration contributions obtained by the Potential Energy Distribution (PED). Intensities are indicated without normalization to allow comparison between the different forms: this comparison must be done with care, taking into account the lack of accuracy of intensity calculations. We discuss here these values to compare the features of the two molecules and therefore we do not introduce any scaling factor to better fit experimental data. The main frequency features due to strong $\mathrm{H}$-bonding and electronic delocalisation are low $v_{\mathrm{OH}}$ and $v_{\mathrm{C}=\mathrm{O}}$ frequencies and high $\tau_{\mathrm{OH}}$ frequency. This also induces a strong vibration mixing which prevents from identifying clearly the features related to the other vibrations. The $v_{\mathrm{OH}}$ frequency is lower for AA $\left(3023 \mathrm{~cm}^{-1}\right)$ than for MA $\left(3135 \mathrm{~cm}^{-1}\right)$ and the same feature is observed for the $v_{\mathrm{C}=\mathrm{O}}$ mode $\left(1674 \mathrm{~cm}^{-1}\right.$ for $\mathrm{AA}$ and $1692 \mathrm{~cm}^{-1}$ for $\mathrm{MA}$ ), whereas the $\tau_{\mathrm{OH}}$ frequency is higher for AA $\left(1003 \mathrm{~cm}^{-1}\right)$ than for MA $\left(937 \mathrm{~cm}^{-1}\right)$. This is once again consistent with an $\mathrm{H}$-bond stronger for AA than for MA. It should be noted that in the case of $\mathrm{AA}$, the $\mathrm{O}-\mathrm{H}$ stretching vibration is pure whereas in the case of MA, it is coupled with the central $\mathrm{C}-\mathrm{H}$ stretching (15\% in the PED), whose calculated frequency is close $\left(3188 \mathrm{~cm}^{-1}\right)$, in agreement with previous calculations $[49,50]$.

Figure $3, a-c$ shows an overview of the calculated frequencies for the $v_{\mathrm{OH}}$, the $v_{\mathrm{C}=\mathrm{O}}$, the $v_{\mathrm{C}=\mathrm{C}}$ modes of the seven non-chelated rotamers. The $v_{\mathrm{OH}}$ frequencies are clearly split in two groups for MA, a low-frequency (and low-intensity) group at $3790-3800 \mathrm{~cm}^{-1}$ corresponding to the XXC rotamers, and a high-frequency (and high-intensity) group at $3848-3862 \mathrm{~cm}^{-1}$ corresponding to the XXT rotamers. A similar classification, although frequency splitting between the two groups is lower, is observed in the case of AA. This difference in $\mathrm{XXC} / \mathrm{XXT} v_{\mathrm{OH}}$ splittings between $\mathrm{AA}$ and $\mathrm{MA}$ can be related to the difference in $\mathrm{XXC} / \mathrm{XXT} \mathrm{O}-\mathrm{H}$ bond length alternate features: this latter feature is more noticeable for MA than for $\mathrm{AA}$, in agreement with a more noticeable frequency splitting. The two most intense modes are in the $v_{\mathrm{C}=\mathrm{O}} / v_{\mathrm{C}=\mathrm{C}}$ region, for which $\mathrm{C}=\mathrm{C}$ and $\mathrm{C}=\mathrm{O}$ stretchings are strongly coupled. The PED analysis shows that $v_{\mathrm{C}=\mathrm{C}}$ vibration generally corresponds to the lowest frequency, except in the case of the TXT forms of AA. The mean $v_{\mathrm{C}=\mathrm{O}}$ frequency is lower for AA than for MA, indicating that, similarly to what is observed for the chelated forms, the electronic delocalisation is also larger for AA than for MA for the non-chelated forms. This can be correlated to the $\mathrm{C}=\mathrm{O}$ bond length of the non-chelated forms which is larger for AA (121.8-122.4 pm) than for MA (121.4-121.7 pm). Figure 3,c also shows that the $v_{\mathrm{C}=\mathrm{O}}$ frequencies are grouped, TXX frequencies being lower than CXX frequencies, and CTT frequencies being the highest. This region is especially interesting for vibrational assignment $[45,46]$ by considering the difference $\Delta v=\left|v_{\mathrm{C}=\mathrm{O}}-v_{\mathrm{C}=\mathrm{C}}\right|$, this value ranging between 90 and $8 \mathrm{~cm}^{-1}$ in the case of $\mathrm{AA}$ and allowing to clearly discriminate between rotamers. Figure 3,d shows that the same ordering in $\Delta v$ values is obtained 
Table 3. Calculated frequencies (in $\mathrm{cm}^{-1}$ ) and intensities (in $\mathrm{km} \cdot \mathrm{mol}^{-1}$, italic) of the most intense vibrational modes of MA and AA, calculated with the B3LYP/6-311++G(2d,2p) model chemistry. The contributions of the potential energy distribution higher than $30 \%$ are indicated for each mode. As in Table 1, bold characters emphasize some special features.

\begin{tabular}{|c|c|c|c|c|c|c|c|}
\hline & $v_{\mathrm{OH}}$ & \multicolumn{2}{|c|}{$v_{\mathrm{C}=\mathrm{O}} / v_{\mathrm{C}=\mathrm{C}}$ region } & \multicolumn{3}{|c|}{$\delta_{\mathrm{OH}} / v_{\mathrm{CO}} / v_{\mathrm{CC}}$ region } & $\tau_{\mathrm{OH}}$ \\
\hline \multicolumn{8}{|c|}{ MA } \\
\hline $\mathrm{CCC}$ & $\begin{array}{c}3135213 \\
v_{\mathrm{OH}}\end{array}$ & $\begin{array}{c}1692225 \\
v_{\mathrm{C}=\mathrm{O}}\end{array}$ & $\begin{array}{c}1627259 \\
\delta_{\mathrm{OH}}\end{array}$ & $\begin{array}{c}1391109 \\
\delta_{\mathrm{OH}}{ }^{v} \mathrm{CO}\end{array}$ & $\begin{array}{c}1287163 \\
v_{\mathrm{CO}}\end{array}$ & $\begin{array}{c}100147 \\
v_{\mathrm{CC}}\end{array}$ & $\begin{array}{c}93760 \\
\tau_{\mathrm{OH}}\end{array}$ \\
\hline CCT & $\begin{array}{c}3847134 \\
v_{\mathrm{OH}}\end{array}$ & $\begin{array}{c}1767160 \\
v_{\mathrm{C}=\mathrm{O}}\end{array}$ & $\begin{array}{c}1666333 \\
v_{\mathrm{C}=\mathrm{C}}\end{array}$ & $\begin{array}{c}1311196 \\
v_{\mathrm{CO}}\end{array}$ & $\begin{array}{c}127681 \\
\delta_{\mathrm{OH}}\end{array}$ & $\begin{array}{c}92077 \\
v_{\mathrm{CC}}\end{array}$ & $\begin{array}{c}32299 \\
\tau_{\mathrm{OH}}\end{array}$ \\
\hline СTC & $\begin{array}{c}379272 \\
v_{\mathrm{OH}}\end{array}$ & $\begin{array}{c}1757122 \\
v_{\mathrm{C}=\mathrm{O}}\end{array}$ & $\begin{array}{c}1640644 \\
v_{\mathrm{C}=\mathrm{C}}\end{array}$ & $\begin{array}{c}132655 \\
\delta_{\mathrm{C}=\mathrm{CH}}\end{array}$ & $\begin{array}{l}1159147 \\
\delta_{\mathrm{OH}}{ }^{v} \mathrm{CO}\end{array}$ & $\begin{array}{c}998109 \\
{ }^{v_{\mathrm{CC}}}\end{array}$ & $\begin{array}{c}\mathbf{5 5 1} 84 \\
\tau_{\mathrm{OH}}\end{array}$ \\
\hline CTT & $\begin{array}{c}3848138 \\
v_{\mathrm{OH}}\end{array}$ & $\begin{array}{c}1762116 \\
v_{\mathrm{C}=\mathrm{O}}\end{array}$ & $\begin{array}{l}1665493 \\
v_{\mathrm{C}=\mathrm{C}}{ }^{v_{\mathrm{C}}=\mathrm{O}}\end{array}$ & $\begin{array}{c}1376162 \\
\delta_{\mathrm{O}=\mathrm{CH}}\end{array}$ & $\begin{array}{c}1247228 \\
v_{\mathrm{CO}}\end{array}$ & $\begin{array}{l}75296 \\
\delta_{\mathrm{O}=\mathrm{CC}}\end{array}$ & $\begin{array}{c}436102 \\
\tau_{\mathrm{OH}}\end{array}$ \\
\hline TCC & $\begin{array}{c}380041 \\
v_{\mathrm{OH}}\end{array}$ & $\begin{array}{c}1743339 \\
v_{\mathrm{C}=\mathrm{O}}\end{array}$ & $\begin{array}{c}1664256 \\
v_{\mathrm{C}=\mathrm{C}}\end{array}$ & $\begin{array}{c}1242166 \\
\delta_{\mathrm{OH}}\end{array}$ & $\begin{array}{c}1153113 \\
v_{\mathrm{CC}}\end{array}$ & $\begin{array}{c}1012102 \\
v_{\mathrm{CO}}\end{array}$ & $\begin{array}{c}\mathbf{5 6 0} 94 \\
\tau_{\mathrm{OH}}\end{array}$ \\
\hline $\mathrm{TCT}$ & $\begin{array}{c}3862149 \\
v_{\mathrm{OH}}\end{array}$ & $\begin{array}{c}1736320 \\
v_{\mathrm{C}=\mathrm{O}}\end{array}$ & $\begin{array}{c}1700159 \\
v_{\mathrm{C}=\mathrm{C}}\end{array}$ & $\begin{array}{c}1296264 \\
\delta_{\mathrm{OH}}\end{array}$ & $\begin{array}{c}115434 \\
v_{\mathrm{CC}}\end{array}$ & $\begin{array}{c}1017133 \\
v_{\mathrm{CO}}\end{array}$ & $\begin{array}{c}285115 \\
\tau_{\mathrm{OH}}\end{array}$ \\
\hline TTC & $\begin{array}{c}379675 \\
v_{\mathrm{OH}}\end{array}$ & $\begin{array}{c}1747326 \\
v_{\mathrm{C}=\mathrm{O}}\end{array}$ & $\begin{array}{c}1680375 \\
v_{\mathrm{C}=\mathrm{C}}\end{array}$ & $\begin{array}{c}124059 \\
v_{\mathrm{CO}}\end{array}$ & $\begin{array}{c}1137377 \\
\delta_{\mathrm{OH}}\end{array}$ & $\begin{array}{c}98643 \\
\mathrm{op}_{\mathrm{HCCO}}{ }^{\text {op }}{ }_{\mathrm{OCCH}}\end{array}$ & $\begin{array}{c}\mathbf{5 3 7} 75 \\
\tau_{\mathrm{OH}}\end{array}$ \\
\hline TTT & $\begin{array}{c}3849143 \\
v_{\mathrm{OH}}\end{array}$ & $\begin{array}{c}1748344 \\
v_{\mathrm{C}=\mathrm{O}}\end{array}$ & $\begin{array}{c}1710264 \\
v_{\mathrm{C}=\mathrm{C}}\end{array}$ & $\begin{array}{c}1340161 \\
\delta_{\mathrm{OH}}\end{array}$ & $\begin{array}{c}1210236 \\
v_{\mathrm{CO}}\end{array}$ & $\begin{array}{c}114783 \\
v_{\mathrm{CC}}\end{array}$ & $\begin{array}{c}41894 \\
\tau_{\mathrm{OH}}\end{array}$ \\
\hline \multicolumn{8}{|c|}{ AA } \\
\hline $\mathrm{CCC}$ & $\begin{array}{c}3023349 \\
v_{\mathrm{OH}}\end{array}$ & $\begin{array}{c}1674429 \\
v_{\mathrm{C}=\mathrm{C}}\end{array}$ & $\begin{array}{l}1643205 \\
v_{\mathrm{C}=\mathrm{O}} \delta_{\mathrm{OH}}\end{array}$ & $\begin{array}{c}1463149 \\
-\end{array}$ & $\begin{array}{c}137797 \\
v_{\mathrm{C}=\mathrm{C}}\end{array}$ & $\begin{array}{c}1270145 \\
v_{\mathrm{CC}}\end{array}$ & $\begin{array}{c}100368 \\
\tau_{\mathrm{OH}}\end{array}$ \\
\hline $\mathrm{CCT}$ & $\begin{array}{c}382081 \\
v_{\mathrm{OH}}\end{array}$ & $\begin{array}{c}1751175 \\
v_{\mathrm{C}=\mathrm{O}}\end{array}$ & $\begin{array}{c}1669412 \\
v_{\mathrm{C}=\mathrm{C}}\end{array}$ & $\begin{array}{c}1308300 \\
\delta_{\mathrm{OH}}\end{array}$ & $\begin{array}{c}120085 \\
-\end{array}$ & $\begin{array}{c}88378 \\
v_{\mathrm{CO}}\end{array}$ & $\begin{array}{c}38882 \\
\tau_{\mathrm{OH}}\end{array}$ \\
\hline СТC & $\begin{array}{c}379744 \\
v_{\mathrm{OH}}\end{array}$ & $\begin{array}{c}1734173 \\
v_{\mathrm{C}=\mathrm{O}}\end{array}$ & $\begin{array}{c}1636571 \\
v_{\mathrm{C}=\mathrm{C}}\end{array}$ & $\begin{array}{c}1466104 \\
\delta_{\mathrm{aCH} 3}\end{array}$ & $\begin{array}{c}1182210 \\
-\end{array}$ & $\begin{array}{c}94971 \\
v_{\mathrm{CC}}\end{array}$ & $\begin{array}{c}48887 \\
\tau_{\mathrm{OH}}\end{array}$ \\
\hline CTT & $\begin{array}{c}382685 \\
v_{\mathrm{OH}}\end{array}$ & $\begin{array}{c}1739198 \\
v_{\mathrm{C}=\mathrm{O}}\end{array}$ & $\begin{array}{l}1657387 \\
v_{\mathrm{C}=\mathrm{C}} v_{\mathrm{C}=\mathrm{O}}\end{array}$ & $\begin{array}{c}1437233 \\
\delta_{\mathrm{CCH}}\end{array}$ & $\begin{array}{c}1237147 \\
\delta_{\mathrm{OH}}\end{array}$ & $\begin{array}{c}948104 \\
v_{\mathrm{CC}}\end{array}$ & $\begin{array}{c}38794 \\
\tau_{\mathrm{OH}}\end{array}$ \\
\hline TCC & $\begin{array}{c}380990 \\
v_{\mathrm{OH}}\end{array}$ & $\begin{array}{c}1707223 \\
v_{\mathrm{C}=\mathrm{O}}\end{array}$ & $\begin{array}{c}1667398 \\
v_{\mathrm{C}=\mathrm{C}}\end{array}$ & $\begin{array}{c}138373 \\
-\end{array}$ & $\begin{array}{c}1280128 \\
v_{\mathrm{CC}}\end{array}$ & $\begin{array}{c}114574 \\
v_{\mathrm{CC}}\end{array}$ & $\begin{array}{c}48171 \\
\tau_{\mathrm{OH}}\end{array}$ \\
\hline TCT & $\begin{array}{c}383992 \\
v_{\mathrm{OH}}\end{array}$ & $\begin{array}{c}171229 \\
v_{\mathrm{C}=\mathrm{C}}\end{array}$ & $\begin{array}{c}1704468 \\
v_{\mathrm{C}=\mathrm{O}}\end{array}$ & $\begin{array}{c}138166 \\
v_{\mathrm{CO}}{ }^{\delta}{ }_{\mathrm{CCH}}\end{array}$ & $\begin{array}{c}1307183 \\
\delta_{\mathrm{OH}}\end{array}$ & $\begin{array}{c}1280143 \\
v_{\mathrm{CC}}\end{array}$ & $\begin{array}{c}33782 \\
\tau_{\mathrm{OH}}\end{array}$ \\
\hline TTC & $\begin{array}{c}380251 \\
v_{\mathrm{OH}}\end{array}$ & $\begin{array}{c}1698168 \\
{ }^{v}{ }_{\mathrm{C}=\mathrm{O}}\end{array}$ & $\begin{array}{c}1671446 \\
v_{\mathrm{C}=\mathrm{C}}\end{array}$ & $\begin{array}{c}129787 \\
{ }^{v_{\mathrm{CC}}}\end{array}$ & $\begin{array}{c}1250108 \\
v_{\mathrm{CO}}\end{array}$ & $\begin{array}{c}1221249 \\
\delta_{\mathrm{OH}}\end{array}$ & $\begin{array}{c}48893 \\
\tau_{\mathrm{OH}}\end{array}$ \\
\hline TTT & $\begin{array}{c}383691 \\
v_{\mathrm{OH}}\end{array}$ & $\begin{array}{c}170325 \\
v_{\mathrm{C}=\mathrm{C}}\end{array}$ & $\begin{array}{c}1694489 \\
v_{\mathrm{C}=\mathrm{O}}\end{array}$ & $\begin{array}{c}1398128 \\
\delta_{\mathrm{OH}} \delta_{s \mathrm{CH} 3}\end{array}$ & $\begin{array}{c}129878 \\
v_{\mathrm{CC}}\end{array}$ & $\begin{array}{l}1211245 \\
\delta_{\mathrm{OH}}{ }^{v} \mathrm{CO}\end{array}$ & $\begin{array}{c}32293 \\
\tau_{\mathrm{OH}}\end{array}$ \\
\hline
\end{tabular}

for the two molecules: the rotamers are grouped by pair XTX/XCX and XTX values are always smaller than XCX values, whereas all TXX values are smaller than CXX values. The skeletal arrangement around the $\mathrm{C}-\mathrm{C}$ bond thus plays the most important role to determine the $\Delta v$ value. The modes chosen in Table 3 are the most intense but are far from pure modes and the $\delta_{\mathrm{OH}} / v_{\mathrm{CO}} / v_{\mathrm{CC}}$ region often shows a strong mix- ing of the different vibrations. On the contrary, the lowest frequency mode displayed in Table $3, \tau_{\mathrm{OH}}$, is always pure (more than $90 \%$ in the PED) and intense: the XXC frequencies are always larger than the XXT frequencies, indicating a stiffer skeleton in the cis configuration, in agreement with geometrical parameters systematically showing a larger $\mathrm{C}=\mathrm{C}-\mathrm{O}$ angle. This behaviour is directly related to that of $v_{\mathrm{OH}}$ and is 

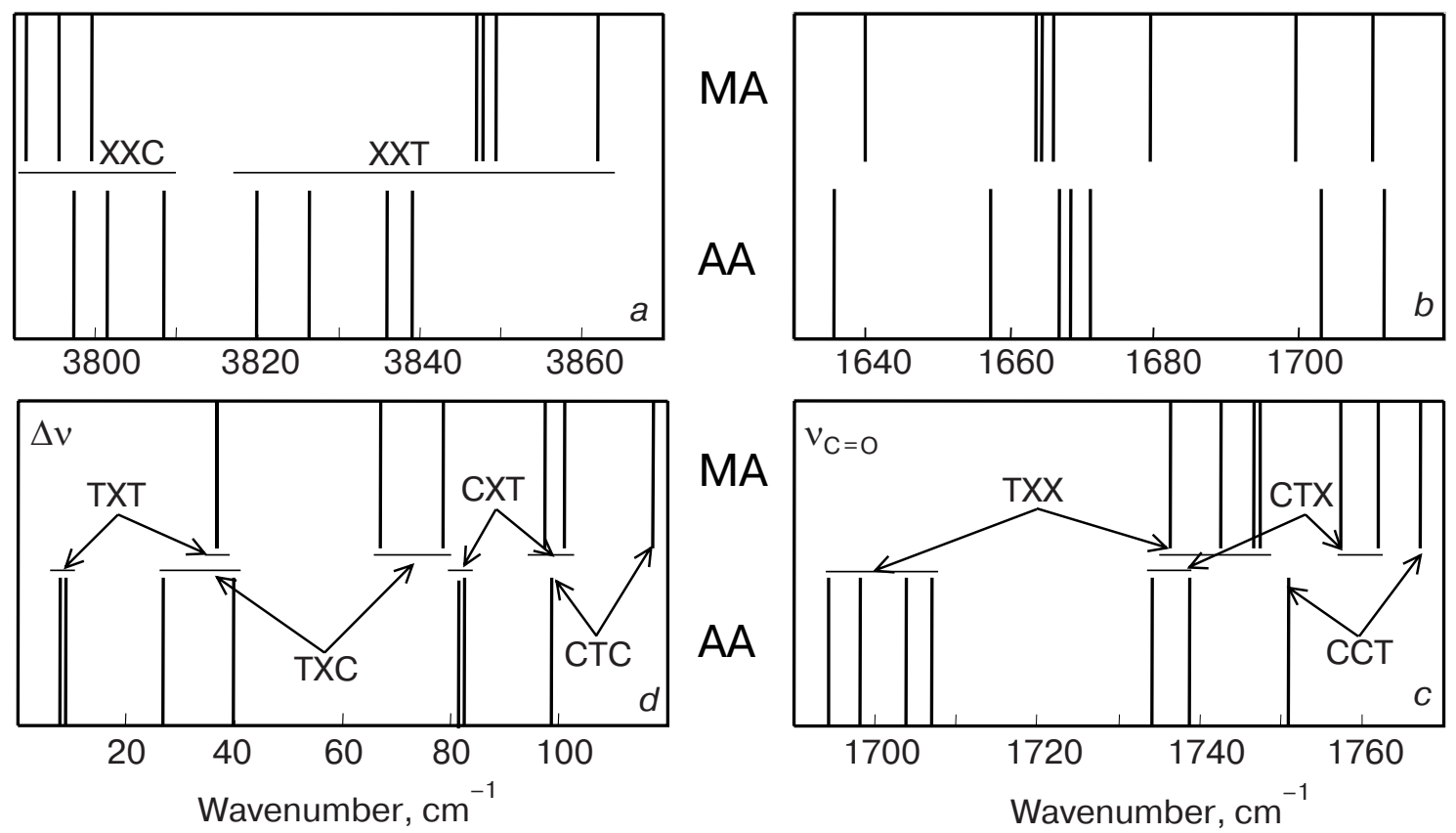

Fig. 3. Bar spectrum of $\mathrm{MA}$ and $\mathrm{AA}$ non-chelated isomer frequencies (in $\mathrm{cm}^{-1}$ ) calculated by the $\mathrm{B} 3 \mathrm{LYP} / 6-311++\mathrm{G}(2 d, 2 p)$ model chemistry: $v_{\mathrm{OH}}$ modes $(a), v_{\mathrm{C}=\mathrm{C}}$ modes $(b), v_{\mathrm{C}=\mathrm{O}}$ modes $(c), \Delta v=\left|v_{\mathrm{C}=\mathrm{O}}-v_{\mathrm{C}=\mathrm{C}}\right|$ values $(d)$.

consistent with the larger electronic delocalisation induced by the cis configuration previously evidenced through geometrical parameters.

\section{Photoisomerizations}

\subsection{Experimental}

Malonaldehyde was synthesised by protonation of sodium malonaldehyde with an ether / $\mathrm{HCl}$ solution, sodium malonaldehyde being synthesised by acid hydrolysis of tetramethoxypropane followed by basification [51,52], whereas acetylacetone was commercially available (99\% purity, Aldrich-Chemie). Molecules were distilled under vacuum and mixed with nitrogen (N60 grade, Air Liquid) in a vacuum line using standard manometric techniques. Roughly $4 \mathrm{~Pa} \cdot \mathrm{m}^{3}$ of a 3:1000 mixture was sprayed onto a goldplated copper cube maintained at $17 \mathrm{~K}$ and the sample was then maintained at $4 \mathrm{~K}$, using a close-cycled helium cryogenerator (Cryomech-PT405). Infrared spectra (FT-IR) were recorded with an IFS $66 / \mathrm{S}$ Bruker spectrometer in reflection-transmission mode, at a $0.12 \mathrm{~cm}^{-1}$ resolution. Broad band UV irradiation were performed using a $300 \mathrm{~W} \mathrm{Hg}$ lamp. Selective IR irradiation were performed using a Nd:YAG pumped $\mathrm{LiNbO}_{3}$ cavity (pulse duration $\sim 15 \mathrm{~ns}$, pulse repetition: $10 \mathrm{~Hz}$ ), leading to a tunable infrared beam whose typical power was $5 \mathrm{~mW}$ and resolution $\sim 5 \mathrm{~cm}^{-1}$ in the $3560-3660 \mathrm{~cm}^{-1}$ region.

\subsection{Malonaldehyde}

Figure 4 shows the effects of UV and IR irradiation for MA isolated in a nitrogen matrix, in the $v_{\mathrm{OH}}$ and $v_{\mathrm{C}=\mathrm{O}} / v_{\mathrm{C}=\mathrm{C}}$ regions. Figure $4, a$ shows the spectrum obtained after deposition: no band is present in this $v_{\mathrm{OH}}$ region, as expected due to the large red-shift $[37,38]$ of this mode. In addition, the broadening of this vibration is large for the isolated molecule and is expected to be even larger for the molecule in a solidstate medium: this mode is therefore not observed for the molecule isolated in matrices [53,54]. According to our PED analysis, the two broad and structured bands at $1652 \mathrm{~cm}^{-1}$ (FWHM: $\sim 7 \mathrm{~cm}^{-1}$ for the main peak) and 1593 (FWHM: $\sim 15 \mathrm{~cm}^{-1}$ ) have a dominant $v_{\mathrm{C}=\mathrm{O}}$ and $\delta_{\mathrm{OH}}$ contribution, respectively. Figure $4, b$ shows the difference spectrum obtained after a $10 \mathrm{~min}$ irradiation with a $\mathrm{Hg}$ lamp. Free $v_{\mathrm{OH}}$ vibration bands clearly appears, indicating the opening of the chelated structure; consistently, in the $v_{\mathrm{C}=\mathrm{O}} / v_{\mathrm{C}=\mathrm{C}}$ region, the two broad bands totally disappear and a complex set of new bands appear. The $v_{\mathrm{OH}}$ region shows two series of bands, at high frequency between 3650 and $3600 \mathrm{~cm}^{-1}$ and at low frequency between 3600 and $3550 \mathrm{~cm}^{-1}$. These two sets of bands are correlated to the two sets of calculated frequencies (Fig. 3,a) and this shows the presence of at least two different types of rotamers, belonging to $\mathrm{XXT}$ and $\mathrm{XXC}$ groups, respectively. The complexity of the $v_{\mathrm{C}=\mathrm{O}} / v_{\mathrm{C}=\mathrm{C}}$ region indicates that probably more than one rotamer per group is formed. In fact, Fig. 4,c shows the effect 


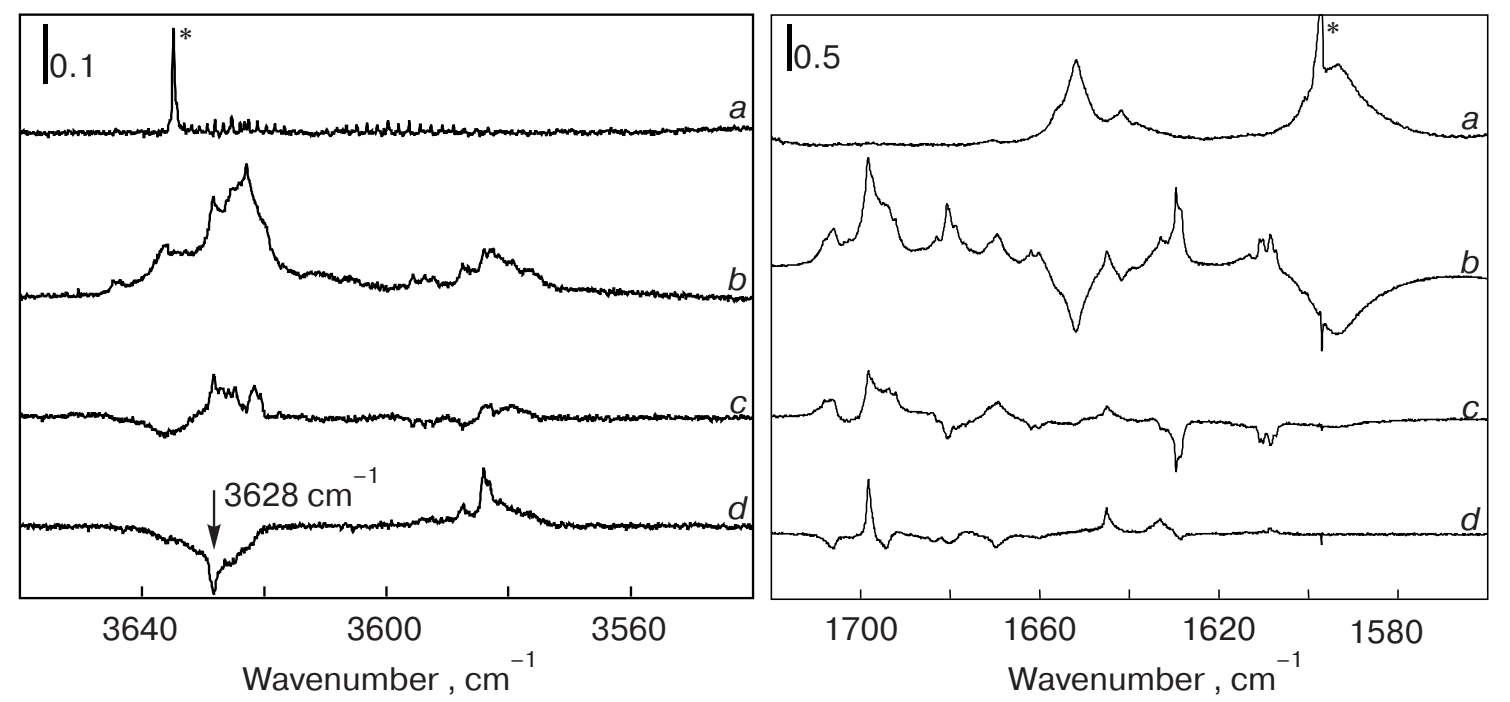

Fig. 4. Infrared spectra of malonaldehyde isolated in a nitrogen matrix at $T=4 \mathrm{~K}, \mathrm{MA}: \mathrm{N}_{2} \sim 5: 1000$. After deposition $(a)$, difference spectrum after a $10 \mathrm{~min} \mathrm{Hg}$ lamp irradiation minus $a(b)$, difference spectrum after minus before an additional $95 \mathrm{~min} \mathrm{Hg}$ lamp irradiation $(c)$, difference spectrum after minus before a 35 min infrared irradiation at $3628 \mathrm{~cm}^{-1}(d)$. The asterisk designates water impurity originating from malonaldehyde synthesis.

of a long irradiation (difference spectrum between 105 min irradiation and $10 \mathrm{~min}$ irradiation, this latter irradiation corresponding to that shown in Fig. 4,b): decreases (at 3636 and $3587 \mathrm{~cm}^{-1}$ ) and increases (at $3628 / 3622$ and $3584 / 3576 \mathrm{~cm}^{-1}$ ) are now observed among each group, indicating the presence of at least four different species. After the total conversion of the chelated form into non-chelated forms, we observe interconversion within the non-chelated forms. The intensities of the increasing / decreasing bands at low frequencies are clearly lower than the intensities of the decreasing/increasing bands at high frequencies, in agreement with what is expected by calculations. Finally, Fig. 4, $d$ shows the effect of an additional selective IR irradiation centered at $3628 \mathrm{~cm}^{-1}$. This $v_{\mathrm{OH}}$ excitation is more selective than the previous UV excitation and the main decrease of the excited band is correlated to a main increase at $3584 \mathrm{~cm}^{-1}$. The reverse effect is observed by exciting at $3584 \mathrm{~cm}^{-1}$. Irradiation have also been performed at 3622 and $3576 \mathrm{~cm}^{-1}$ and have shown similar interconversion. The complete vibrational assignment of all the bands is done by correlating along the whole spectrum the increases and the decreases observed for different irradiation times, for different types of irradiation, as well as for temperature changes. In particular, temperature effects allow us to differentiate interconversion between rotamers from trapping site effects. The assignment is still puzzling and is currently under study: the preliminary analysis indicates the presence of the TTX and TCX pairs.

\subsection{Acetylacetone}

Figure 5 shows the effects of UV and IR irradiation for AA isolated in a nitrogen matrix in the $v_{\mathrm{OH}}$ and $v_{\mathrm{C}=\mathrm{O}} / v_{\mathrm{C}=\mathrm{C}}$ regions. Figure $5, a$ shows the spectrum obtained after deposition: the features mentioned for the $v_{\mathrm{OH}}$ vibration are similar to those of MA $[35,55,56]$. According to the PED analysis, the two broad bands at $1638 \mathrm{~cm}^{-1}$ (FWHM: $\sim 20 \mathrm{~cm}^{-1}$ ) and 1614 (FWHM: $\sim 28 \mathrm{~cm}^{-1}$ ) have a dominant $v_{\mathrm{C}=\mathrm{C}}$ and $v_{\mathrm{C}=\mathrm{O}}$ contribution, respectively. Figure $5, b$ shows the difference spectrum obtained after a 120 min irradiation with a $\mathrm{Hg}$ lamp. The $v_{\mathrm{OH}}$ region shows two series of bands, at high frequency between 3630 and $3600 \mathrm{~cm}^{-1}$, and at low frequency between 3600 and $3560 \mathrm{~cm}^{-1}$. Thin bands appear in the $v_{\mathrm{C}=\mathrm{O}} / v_{\mathrm{C}=\mathrm{C}}$ region and, contrary to what is observed for MA, the original bands do not completely disappear. Figure 5, $c$ shows the difference spectrum obtained after an irradiation at $3585 \mathrm{~cm}^{-1}$ : the two sets of increasing and decreasing bands in the $v_{\mathrm{C}=\mathrm{O}} / v_{\mathrm{C}=\mathrm{C}}$ region are wellseparated ( $\Delta \nu \sim 76$ and $89 \mathrm{~cm}^{-1}$, respectively) and should therefore unambiguously be assigned to two rotamers among CCT, CTT and CTC (Fig. 3,d). In addition, this infrared excitation does not bring enough energy to induce a rotation around $\mathrm{C}=\mathrm{C}$ and we can deduce that these species are CTT and CTC. Figure $5, d$ shows another example of selective infrared irradiation at $3622 \mathrm{~cm}^{-1}$. The main increasing $v_{\mathrm{OH}}$ band is in the same group of high-frequency $v_{\mathrm{OH}}$, whereas the main increasing or decreasing bands in the $v_{\mathrm{C}=\mathrm{O}} /{ }^{{ }_{\mathrm{C}}=\mathrm{C}}$ region are separated by only $\Delta v \sim 33$ and $16 \mathrm{~cm}^{-1}$. This latter feature shows that this irradiation 


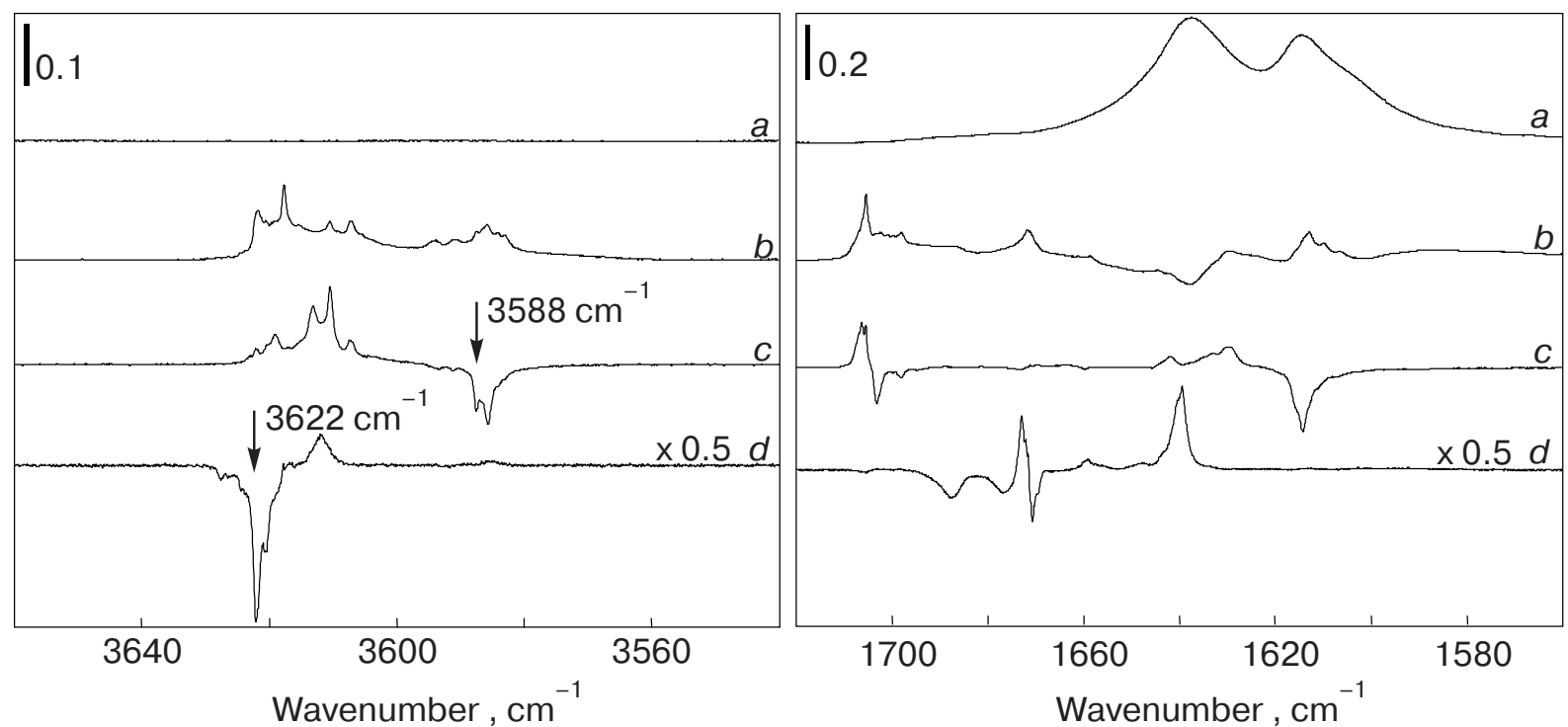

Fig. 5. Infrared spectra of acetylacetone isolated in a nitrogen matrix at $T=4 \mathrm{~K}, \mathrm{AA}: \mathrm{N}_{2} \sim 3: 1000$. After deposition (a), difference spectrum after a $120 \mathrm{~min} \mathrm{Hg}$ lamp irradiation minus $a(b)$, difference spectrum after minus before a 45 min infrared irradiation at $3585 \mathrm{~cm}^{-1}(c)$, difference spectrum after minus before a $11 \mathrm{~min}$ infrared irradiation at $3622 \mathrm{~cm}^{-1}(d)$.

is a TXT $\leftrightarrow$ TXC interconversion (Fig. 3,d). The information of the $v_{\mathrm{OH}}$ region is less clear than for MA, as expected by calculations and further investigation in the whole spectral domain shows that only the CTT/CTC and the TCT/TCC pairs are formed upon irradiation.

\subsection{Discussion}

The CCC forms of the two molecules clearly show vibrational features characteristic to strong hydrogen bonding like for example the shift and the broadening of the $v_{\mathrm{OH}}, v_{\mathrm{C}=\mathrm{O}}, v_{\mathrm{C}=\mathrm{C}}$ and $\tau_{\mathrm{OH}}$ modes. No evidence for proton tunnelling is found, similarly to what is observed for molecules isolated in argon matrices $[42,53]$, probably due to a dynamical damping of the proton movement through the matrix phonons. To our knowledge, among similar molecules having an $\mathrm{H}$ position in a symmetric double well-potential between $\mathrm{O}$ atoms, this proton transfer in the ground electronic state has been observed in the case of matrix isolation only for tropolone [57] and only for the two modes the most involved in this proton transfer, i.e., the stretchings of the $\mathrm{OH}$-bond and of the $\mathrm{H}$-bond. In this case, proton transfer occurs in a 5 -atom quasi-ring which is probably stiffer and less coupled to the environment than the 6-atom quasi-ring of MA and AA. It should be noted that temperature changes necessary to observe population changes and to unambiguously assign a tunnelling effect are very easy to get in cryogenic matrices for a tunnelling splitting measured at $\sim 21.6 \mathrm{~cm}^{-1}$ in the case of MA: cryogenic matrix isolation would have been a nice way to evidence proton tunnelling without this efficient damping. We focus here on the observed $v_{\mathrm{C}=\mathrm{O}}$ and $v_{\mathrm{C}=\mathrm{C}}$ modes Both calculations and experiments show that they are at lower frequency and that the $\Delta v$ value is smaller for AA than for MA, in agreement with stronger $\mathrm{H}$-bonding for AA. The bandwidth is nevertheless very large when compared to that of non-chelated forms (Figs. 4 and 5) and this indicates that $\mathrm{H}$-bonding efficiently acts as a doorway for relaxation through phonons. In addition, broadening is larger for AA than for MA, but this is not the case for the non-chelated forms, for which the bandwidths are similar for AA and MA. This suggests that the enhancement of H-bonding plays a larger role than the presence of the methyl groups in this broadening effect. Further analyses are nevertheless necessary to definitely conclude: in particular it is necessary to test the homogeneity of the bands observed for the non-chelated species.

The most striking feature is that irradiating the $\pi \rightarrow \pi^{*}$ transition of these molecules isolated in nitrogen matrices lead for both molecules to isomerisation within the enolic rotamers, and not to another isomerisation as that to the keto form, whereas dissociation is observed in the gas phase [58]; the solidstate environment probably prevents from dissociation through a cage effect. In the case of MA, broad band irradiation with a $\mathrm{Hg}$ lamp lead to the complete conversion to the non-chelated form while in the case of $\mathrm{AA}$, the conversion is limited to $\sim 80 \%$, indicating the existence of a photostationary equilibrium and the existence of non-chelated $\rightarrow$ chelated back-reactions. For MA and AA isolated in a nitrogen matrix, the UV absorptions of the chelated forms have been measured at 265 and $270 \mathrm{~nm}$, respectively, whereas the non- 
chelated UV absorptions have been measured at $224 \mathrm{~nm}$ for MA (to be published) and at 230 and $249 \mathrm{~nm}$ for AA [46]. Chelated $\rightarrow$ non-chelated, as well as non-chelated $\rightarrow$ chelated back-reactions are thus expected to occur under broad band irradiation. Laser irradiation have allowed us to identify these backreactions in the case of AA [46] and further similar experiments are necessary to also identify the backreactions in the case of MA, and to confirm that they are less efficient. These experiments also give evidence that infrared $v_{\mathrm{OH}}$ excitations easily induce interconversion. Rotating around the single bonds necessitates typically $5-8 \mathrm{kcal} \cdot \mathrm{mol}^{-1}$, whereas rotating around the double bonds necessitates typically $40-50 \mathrm{kcal} \cdot \mathrm{mol}^{-1}$ and therefore, only rotation around single bonds are expected to occur when exciting with infrared irradiation. The only conversion observed here is $\mathrm{XXC} \leftrightarrow \mathrm{XXT}$ and this shows that $\mathrm{O}-\mathrm{H}$ stretching couples efficiently with a neighbouring vibrator as the rotation around the $(\mathrm{C}-\mathrm{O})$-bond, but that far-neighbour mode coupling is too weak to insure conversion. Conversely, a similar study [59] of IR-induced interconversions between a $\mathrm{H}$-bonded form of malonic acid (which also possess a quasi symmetric $\mathrm{H}$-bond in a HOCCCO quasi-ring), and non H-bonded forms, has led to a more complex rotation around both $\mathrm{C}-\mathrm{O}$ and $\mathrm{C}-\mathrm{C}$ single bonds: this is due to the different nature of the rings, those of AA or MA being clearly reinforced by a $\mathrm{C}=\mathrm{C}$ double bond compared to that of malonic acid. These vibrational excitations are in any case a powerful tool to discriminate and identify the rotamers. On the other hand, electronic excitations suggest complex reactivity phenomena, the following questions are assessed. Why only four among the seven non-chelated rotamers are observed? Does isomerisation occur in the $S_{2}, S_{1}$ or $S_{0}$ state? Is there intersystem crossing, as suggested by a recent study [34]? For this latter point, isolation in cryogenic matrices can bring valuable information: the heavyatom effect, well-known to facilitate intersystem crossing, increases in the series $\mathrm{Ne}, \mathrm{Ar}, \mathrm{Kr}, \mathrm{Xe}$, and reactivity rates can be analysed by varying the host material. This point is currently in progress.

\section{Conclusion}

The comparison of some calculated and measured properties of the eight enolic rotamers of malonaldehyde and acetylacetone has been investigated through ground-state energy, geometry and vibrational frequency calculations with the B3LYP / 6-311++G $(2 d, 2 p)$ model chemistry, and through photoinduced isomerisation experiments for the molecules isolated in nitrogen matrices. The re- lative positions of vibrational bands as $v_{\mathrm{OH}}, v_{\mathrm{CO}}, \tau_{\mathrm{OH}}$ give a clear experimental evidence that $\mathrm{H}$-bonding is stronger for AA, as expected due to the electron release induced by the methyl groups. The comparison of geometrical parameters and vibrational frequencies shows that calculations correctly take into account this H-bond enhancement. The energy difference between chelated CCC and the non-chelated CCT forms gives an estimation of the hydrogen bond strength; this estimation is nevertheless blurred by other contributions like possible steric hindrance induced by the rotation. We get here a rough estimation of $1.7 \mathrm{kcal} \cdot \mathrm{mol}^{-1}$ for the hydrogen bond energy difference between AA and MA.

Alternate cis/trans properties are found only for the cis/trans configuration around the $\mathrm{C}-\mathrm{O}$ bond, with evidence for a local larger electronic delocalisation for the cis configuration: this effect is even larger for AA. Although whole skeleton changes are involved, the other cis/trans configurations around the $\mathrm{C}-\mathrm{C}$ or the $\mathrm{C}=\mathrm{C}$ bonds do not lead to similar alternate properties, probably because several types of repulsive or attractive interactions are competing.

Reactivity has been analysed by means of FT-IR spectrometry and vibrational analysis. We have shown that, contrary to what is observed in gas phase, in nitrogen matrices UV $\pi \rightarrow \pi^{*}$ excitation produces rotamers, only some among the seven rotamers being observed. Selective $\mathrm{O}-\mathrm{H}$ stretching excitation has revealed a useful tool for identifying these rotamers. The observed rotamers are not the same for AA and for MA, suggesting complex reactional processes and further experimental and theoretical studies are necessary to analyse the relaxation pathways involved in this photochemistry.

1. W.F. Rowe, Jr., R.W. Duerst, and E.B. Wilson, J. Am. Chem. Soc. 98, 4021 (1976).

2. A.H. Lowry, C. George, P. D'Antonio, and J. Karle, J. Am. Chem. Soc. 93, 6399 (1971).

3. A.L. Andersen and S.H. Bauer, J. Mol. Struct. 12, 381 (1972).

4. R. Boese, M.Y. Antipin, D. Blaser, and K.A. Lyssenko, J. Phys. Chem. B102, 8654 (1998).

5. A. Camerman, D. Mastropaolo, and N. Camerman, $J$. Am. Chem. Soc. 105, 1584 (1983).

6. K. Iijima, A. Ohnogi, and S. Shibata, J. Mol. Struct. 156, 111 (1987).

7. A.L. Andreassen and S.H. Bauer, J. Mol. Struct. 12, 381 (1972).

8. R. Srinivasan, J.S. Feenstra, S.T. Park, S. Xu, and A.H. Zewail, J. Am. Chem. Soc. 126, 2266 (2003).

9. S.L. Baughcum, Z. Smith, E.B. Wilson, and R.W. Duerst, J. Am. Chem. Soc. 106, 2260 (1984).

10. P. Turner, S.L. Baughcum, S.L. Coy, and Z. Smith, J. Am. Chem. Soc. 106, 2265 (1984). 
11. T. Carrington, Jr. and W.H. Miller, J. Chem. Phys. 84, 4364 (1986).

12. G. Karlström, B. Jönsson, B. Roos, and H. Wennerstrom, J. Am. Chem. Soc. 98, 6851 (1976).

13. M.J. Frisch, A.C. Scheiner, H.F. Shaefer III, and J.S. Binkley, J. Chem. Phys. 82, 4194 (1985).

14. N. Shida, P.F. Barbara, and J.E. Almlof, J. Chem. Phys. 91, 4061 (1989).

15. Z. Latajka and S. Scheiner, J. Phys. Chem. 96, 9764 (1992).

16. E. Bosch, M. Moreno, and J.M. Lluch, J. Am. Chem. Soc. 114, 2072 (1992)

17. K. Luth and S. Scheiner, Int. J. Quantum Chem. Suppl. 27, 419 (1993).

18. K. Luth and S. Scheiner, J. Phys. Chem. 98, 3582 (1994).

19. K.B. Wiberg, J. Ochterski, and A. Sheitweiser, J. Am. Chem. Soc. 118, 8291 (1996).

20. V. Barone and C. Adamo J. Chem. Phys. 105, 11007 (1996).

21. S. Sirois, E.I. Proynov, D.T. Nguyen, and D.R. Salahub, J. Chem. Phys. 107, 6770 (1997).

22. A.L. Sobolewski and W. Domcke, J. Phys. Chem. A103, 4494 (1999).

23. S. Sadhukhan, D. Munoz, C. Adamo, and G.E. Scuseria, Chem. Phys. Lett. 30683 (1999).

24. V.A. Benderskii, E.V. Vetoshkina, I.S. Irgibaeva, and H.P. Trommsdorff, Chem. Phys, 262, 393 (2000).

25. D. Babic, S.D. Bosanac, and N. Doslic, Chem. Phys. Lett. 358, 337 (2002).

26. G. Kovacevics, T. Hrenar, and N. Doslic, Chem. Phys. 293, 41 (2002).

27. R. Meyer and T.-K. Ha, Mol. Phys. 101, 3263 (2003).

28. M.A. Rios and J. Rodriguez, J. Mol. Struct. (Theochem) 228, 149 (1990).

29. J.J. Dannenberg and R. Rios, J. Am. Chem. Soc. 98, 6714 (1994).

30. K. Hinsen and B. Roux, J. Chem. Phys. 106, 3567 (1996).

31. J.A. Erickson, J. Org. Chem. 60, 1626 (1995).

32. V.B. Delchev and G.S. Nikolov, Monatshefte für Chemie 131, 107 (2000).

33. V.B. Delchev and H. Mikosch, Russian J. Phys. Chem. 78, 1445 (2003).

34. X.-B. Chen, W.-H. Fang, and D.L. Phillips, J. Phys. Chem. A110, 4434 (2006).

35. S.F. Tayyari and F. Milani-Nejad, Spectrochim. Acta A56, 2679 (2000).

36. J. Mavri and J. Grdadolnik, J. Phys. Chem. A105, 2045 (2001)
37. C.J. Seliskar and R.E. Hoffmann, J. Mol. Spectrosc. 96, 146 (1982).

38. Z. Smith, E.B. Wilson, and R.W. Duerst, Spectrochim. Acta A39, 1117 (1983).

39. G. Buemi and C. Gandolfo, J. Chem. Soc., Faraday Trans. 85, 215 (1989).

40. S.H. Bauer and C.F. Wilcox, Chem. Phys. Lett. 279, 122 (1997).

41. D.P. Chong and C.-H. Hu, J. Electron Spectrosc. Relat. Phenom. 94, 181 (1998).

42. P. Roubin, T. Chiavassa, P. Verlaque, L. Pizzala, and H. Bodot, Chem. Phys. Lett. 175, 655 (1990).

43. T. Chiavassa, P. Verlaque, L. Pizzala, A. Allouche, and P. Roubin, J. Phys. Chem. 97, 5917 (1993).

44. N. Nagashima, S. Kudoh, M. Takayanagi, and M. Nakata, J. Phys. Chem. A105, 10832 (2001).

45. S. Coussan, C. Manca, Y. Ferro, and P. Roubin, Chem. Phys. Lett. 370, 118 (2003).

46. S. Coussan, Y. Ferro, A. Trivella, M. Rajzmann, P. Roubin, R. Wieczorek, C. Manca, P. Piecuch, K. Kowalski, M. Wloch, S.A. Kucharski, and M. Musial, J. Phys. Chem. A110, 3920 (2006).

47. M.J. Frisch et al., Rev. A.2, Gaussian Inc., Pittsburgh PA (1998).

48. M.J. Frisch, G.W. Trucks, H.B. Schlegel, et al., Gaussian03 Rev. A.1, Gaussian Inc., Pittsburgh (2003).

49. S.F. Tayyari and F. Milani-Nejad, Spectrochim. Acta A54, 255 (1998).

50. A. Alparone and S. Millefiori, Chem. Phys. 290, 15 (2003).

51. W.O. George and V.G. Mansell, J. Chem. Soc. B2, 132 (1968).

52. V. Nair, D.E. Vietti, and C.S. Cooper, J. Am. Chem. Soc. 103, 3030 (1981).

53. D.W. Firth, P.F. Barbara, and H.P. Trommsdorff, Chem. Phys. 136, 349 (1989).

54. T. Chiavassa, P. Roubin, L. Pizzala, P. Verlaque, A.Allouche, and F. Marinelli, J. Phys. Chem. 96, 10659 (1992).

55. T. Chiavassa, P. Verlaque, L. Pizzala, and P. Roubin, Spectrochim. Acta A50, 343 (1994).

56. J. Mavri and J. Grdadolnik, J. Phys. Chem. 105, 2039 (2001).

57. R.L. Redington, T.E. Redington, and J.M. Montgomery, J. Chem. Phys. 113, 2304 (2000).

58. H.P. Upadhyaya, A. Kumar, and P.D. Naik, J. Chem. Phys. 118, 2590 (2003).

59. E.M.S. Maçôas, R. Fausto, J. Lundell, M. Pettersson, L. Khriachtchev, and M. Räsänen, J. Phys. Chem. A104, 11725 (2000). 